\title{
The regional dimension of education hubs: Leading and brokering geopolitics
}

Jack T. Lee

Graduate School of Education

\section{Abstract}

Several education hubs have emerged in the last decade in Asia and the Middle East. These ambitious policy initiatives share a common interest in cross-border higher education even though diverse rationales underpin their development. While some claim to be an international education hub, others claim to be a regional education hub or simultaneously international and regional. Considerable rhetoric and assumptions of uniformity exist in the discourse of education hub development. This paper clarifies the regional dimension of education hubs in terms of concepts, rationales, and strategies of regional engagement. Policymakers pursue different definitions of region as they leverage higher education to gain geopolitical influence in targeted spheres. Furthermore, the distinction between the role of a regional leader and regional broker presents different opportunities for an education hub. The paper compares the development of three key education hubs in Asia: Malaysia, Singapore, and Hong Kong.

$\begin{array}{ll}\text { Original language } & \text { English } \\ \text { Pages (from-to) } & 69-89 \\ \text { Number of pages } & 21 \\ \text { Journal } & \text { Higher Education Policy } \\ \text { Volume } & 28 \\ \text { Issue number } & 1 \\ \text { State } & \text { Published - Mar 1 2015 }\end{array}$

Lee, J. T. (2015). The regional dimension of education hubs: Leading and brokering geopolitics. Higher Education Policy, 28(1), 69-89. DOI: 10.1057/hep.2014.32 